\title{
GMR
}

\section{Phenotypic diversity of starch granules in cassava germplasm}

\author{
L.M. Vasconcelos ${ }^{1}$, A.C. Brito ${ }^{2}$, C.D. Carmo ${ }^{1}$, P.H.G.A. Oliveira ${ }^{1}$ and \\ E.J. Oliveira ${ }^{2}$ \\ ${ }^{1}$ Centro de Ciências Agrárias Ambientais e Biológicas, \\ Universidade Federal do Recôncavo da Bahia, Cruz das Almas, BA, Brasil \\ ${ }^{2}$ Núcleo de Recursos Genéticos e Desenvolvimento de Variedades, \\ Embrapa Mandioca e Fruticultura, Cruz das Almas, BA, Brasil \\ Corresponding author: E.J. Oliveira \\ E-mail: eder.oliveira@embrapa.br
}

Genet. Mol. Res. 16 (2): gmr16029276

Received September 14, 2016

Accepted March 8, 2017

Published April 13, 2017

DOI http://dx.doi.org/10.4238/gmr16029276

Copyright (C) 2017 The Authors. This is an open-access article distributed under the terms of the Creative Commons Attribution ShareAlike (CC BY-SA) 4.0 License.

ABSTRACT. Demand for the development of cassava varieties with
different native starches has guided the search for these characteristics in
the germplasm of Manihotesculenta Crantz. Therefore, the objective of this
study was to estimate the genetic diversity of cassava accessions for root
and starch granule characteristics to guide the future industrial application
of this species. Starches from 56 accessions were evaluated for the number
of granules in $1 \mathrm{~g}$ of starch (NTG), area (AG, $\left.\mathrm{mm}^{2}\right)$, length (LG, mm),
width (WG, mm), starch granule roundness (Round), dry matter content
in the roots (DMC, \%), pulp color (PulCo), and cyanogenic compounds
(HCN). Images captured by light microscopy were used to determine the
average phenotypic values, and these were further analyzed by principal
component analysis (PCA) considering mixed data (quantitative and
qualitative). Significant differences between the cassava accessions for all
traits measured revealed wide variability in starch granule characteristics.
Four diversity groups with better fitness for the classification of cassava
accessions based on PulCo were identified, in comparison with HCN.

Genetics and Molecular Research 16 (2): gmr16029276 
Accessions with differential starch characteristics were identified, and crossings for the generation of segregating populations in order to obtain table and industry varieties have been proposed.

Key words: Breeding; Manihot esculenta Crantz; Root; Genetic diversity; Germplasm; Starch

\section{INTRODUCTION}

Cassava (Manihot esculenta Crantz) is one of the most important crops of the $21 \mathrm{st}$ century because of its high adaptability to adverse climate and soil conditions, and its low requirement for agricultural input during production in comparison with other crops. It is used widely for human and animal subsistence and for industrial applications in food, energy, and textiles (Howeler et al., 2013).

Cassava roots are comprised of water (70\%), starch (24\%), fiber (2\%), protein (1\%), and other substances, including minerals (3\%) (Tonukari, 2004). Therefore, the most notable characteristic of cassava is its capacity to accumulate starch in its roots, the content of which varies from 70 to $90 \%$ dry matter content (Baguma, 2004). Furthermore, there is high diversity in the content, composition, physical, and chemical properties of cassava starch (Nuwamanya et al., 2010; Oliveira et al., 2015a; Sanoussi et al., 2015), resulting in its application in different industrial activities.

Starch is synthesized in amyloplasts of plant cells, and is formed by two types of polymers: amylopectin and amylose. Amylose is present as a predominantly linear chain composed of glucose residues linked by $\alpha-1,4$ bonds. In contrast, amylopectin is a branched long chain molecule, consisting of hundreds of glucose chains, $\alpha-1,4$ linked by $\alpha-1,6$ linkages (Hoover, 2001). Most of the known cassava varieties present starch with approximately $20-30 \%$ amylose and $70-80 \%$ amylopectin content (Taggart and Mitchell, 2009). The organization of glucose molecules in starch, including the length of the glucose chain, and the relative amylose/amylopectin ratio influence the morphology and size of the starch granules (Copeland et al., 2009).

In general, cassava starch granules are rounded, oval, or truncated in form (circular with a flat surface on one face) and range in size from 5 to $40 \mu \mathrm{m}$ (Ceballos et al., 2007). According to Lindeboom et al. (2004), starch granules can be grouped into four size classes: large (greater than $25 \mu \mathrm{m}$ ), average (10 to $25 \mu \mathrm{m}$ ), small (5 to $10 \mu \mathrm{m}$ ), and very small (less than $5 \mathrm{~mm}$ ).

Compared with cereals, cassava starch has particular properties that confer enhanced resistance to acid treatments, permitting its use in the composition of unique pastes, which makes it suitable for the production of paper, textiles, sweeteners, alcohol, and monosodium glutamate (Taylor et al., 2012). The complexity of starch biosynthesis results in large natural variability in relation to the amylose/amylopectin ratio, reflecting the diversity in granule morphology (size and shape), which is associated with different functional properties in the food industry (Wani et al., 2012). Moreover, many cassava varieties are used for starch extraction, which allows a variety of starches to be obtained, and particle distribution can vary in size, morphology, and physicochemical properties. The distribution and granule size may result in distinct starch agglomerations, influence its behavior under certain processing conditions, and consequently affect the quality of the final product (Molenda et al., 2006).

In addition to the amylose/amylopectin ratio, molecular weight, and starch granule structure, some reports have shown that granule size can affect the composition, gelatinization paste properties, enzymatic susceptibility, crystallinity, swelling, and starch solubility (Wani et al.,

Genetics and Molecular Research 16 (2): gmr16029276 
2012). All of these characteristics appear to be affected by environmental and agronomic crop conditions as well as by genetic factors, resulting in substantial changes in the functional properties of the starch (Lawal et al., 2011). Although cassava starch has been extensively studied in relation to its paste properties, and for its chemical and physical composition, few studies have investigated the genetic diversity of the distribution, shape, and size of cassava starch granules. Knowledge of the genetic diversity present in germplasm banks is essential when utilizing phenotypic variations in the development of new varieties that can bring functional properties to different industrial applications (Upadhyaya et al., 2007). The aim of this study was to characterize and evaluate the genetic diversity of cassava accessions for starch granule traits, which may contribute to future industrial application and, consequently, to the greater use of genetic resources of M. esculenta.

\section{MATERIAL AND METHODS}

\section{Plant material}

Fifty-six accessions of the Cassava Active Germplasm Bank at Embrapa Cassava \& Fruits (Cruz das Almas, Bahia, Brazil) were collected during 11 months after planting (Table 1). The region has a hot and humid tropical climate, Aw to Am according to the Köppen classification, with average annual temperatures of $24.5^{\circ} \mathrm{C}, 80 \%$ relative humidity, and $1200 \mathrm{~mm}$ annual rainfall. The soil is classified as yellow Latosol dystrophic. The cassava accessions were selected based on their contrasting starch content, cyanogen compound content, and pulp color of the roots.

\section{Starch extraction}

Roots were harvested 11 months after planting. The selected roots were washed in water, following which $1 \mathrm{~kg}$ of pulp was sectioned to complete the extraction process. The selected pieces were ground in a blender using a non-cutting helix (to reduce the shearing of the starch grains and the consequent physical modification) for $90 \mathrm{~s}$ in a 1:1 root to cold water ratio. This process was repeated several times following 1-min pauses.

The crushed material was filtered in voile-type fabric, and through a sieve, to analyze particle size $(220 \mathrm{mesh})$ in a plastic bucket $(5 \mathrm{~L})$. Next, the tritured mass was washed with 3.5 $\mathrm{L}$ cold water. The filtrate was placed in a cold chamber at $5^{\circ} \mathrm{C}$ for $12 \mathrm{~h}$ to enable the starch to settle. The supernatant was discarded and the decanted starch was washed with $20 \mathrm{~mL} \mathrm{95 \%}$ alcohol to accelerate drying. The alcohol was discarded, and the starch was stored in an oven with forced air circulation at $45^{\circ} \mathrm{C}$ until completely dry. The dried starch was then macerated using a mortar and pestle until a finely textured powder was obtained, which was then packed in sealed plastic vacuum bags for further analysis.

\section{Morphological analysis of the starch granules}

To visualize the starch granules, a solution of $1 \mathrm{~g}$ starch and $4 \mathrm{~g}$ water was used to simulate the concentration of starch present in the cassava roots. Subsequently, $0.8 \mathrm{~mL}$ of this solution was mixed with $1.8 \mathrm{~mL} 2 \%$ iodine solution $(2 \mathrm{~g}$ potassium iodide [KI], $0.2 \mathrm{~g}$ iodide [I2], and $100 \mathrm{~mL}$ distilled water). A $0.2-\mathrm{mL}$ volume of this solution was transferred to a Neubauer chamber for observation at 400X magnification under a LEICA optical microscope (DM500, Germany). Digital images were captured using LAS EZ software, which recorded

Genetics and Molecular Research 16 (2): gmr16029276 
the edge quarters of the chamber and the center. Next, the images were processed and analyzed using ImageJ software (Schneider et al., 2012) to determine the following traits: number of granules in $1 \mathrm{~g}$ starch (NTG), granule area $\left(\mathrm{GrAr}, \mathrm{mm}^{2}\right)$, length of granules $(\mathrm{GrLe}, \mu \mathrm{m})$, width of granules $(\mathrm{GrWi}, \mu \mathrm{m})$, granule roundness (GrRo), dry matter content in the roots (DMC, in $\%$, measured by hydrostatic balance, as described by Kawano et al., 1978), pulp color (PuCo as described by Fukuda et al., 2010), and cyanogen compound classification (HCN, measured qualitatively by the picric acid method as described by Onwuka, 2005).

Table 1. Cassava accessions used for starch characterization.

\begin{tabular}{|c|c|c|c|c|}
\hline Genotype & Origin & Obtaining form & Pulp color & Cyanide coumpound classification \\
\hline $98150-06$ & Cruz das Almas (BA) & Breeding & White & Sweet \\
\hline BGM0250 & Ilha dos Frades (BA) & Landrace & Cream & Sweet \\
\hline BGM0394 & Magé (RJ) & Landrace & White & Bitter \\
\hline BGM0507 & - (MT) & Landrace & Yellow & Sweet \\
\hline BGM0540 & União dos Palmares (AL) & Landrace & White & Bitter \\
\hline BGM0620 & Pentecoste (CE) & Landrace & White & Sweet \\
\hline BGM0670 & São Joao Da Barra (RJ) & Landrace & White & Bitter \\
\hline BGM0889 & Tocantinópolis (TO) & Landrace & Cream & Intermediate \\
\hline BGM0982 & $-(\mathrm{AM})$ & Landrace & White & Bitter \\
\hline BGM0989 & Manaus (AM) & Landrace & White & Bitter \\
\hline BGM1078 & Sape $(\mathrm{PB})$ & Landrace & Yellow & Bitter \\
\hline BGM1081 & Goiana (PE) & Landrace & White & Bitter \\
\hline BGM1110 & Araranguá (SC) & Landrace & White & Sweet \\
\hline BGM1127 & Conceição do Coite (BA) & Landrace & Cream & Intermediate \\
\hline BGM1171 & Bragança (PA) & Landrace & White & Bitter \\
\hline BGM1174 & - & Landrace & White & Bitter \\
\hline BGM1178 & - & Landrace & Yellow & Intermediate \\
\hline BGM1180 & - & Landrace & White & Sweet \\
\hline BGM1202 & Cruz das Almas (BA) & Landrace & White & Bitter \\
\hline BGM1313 & São Jose do Belmonte (PE) & Landrace & White & Sweet \\
\hline BGM1327 & Monteiro (PB) & \begin{tabular}{|l|} 
Landrace \\
\end{tabular} & White & Bitter \\
\hline BGM1370 & Juazeirinho (PB) & Landrace & White & Sweet \\
\hline BGM1376 & São Vicente do Seridó (PB) & Landrace & White & Sweet \\
\hline BGM1412 & \begin{tabular}{|l} 
Cruzeta (RN) \\
\end{tabular} & Landrace & White & Intermediate \\
\hline BGM1429 & $\begin{array}{l}\text { Caruaru (PE) } \\
\end{array}$ & Landrace & White & Sweet \\
\hline BGM1437 & Altinho (PE) & Landrace & White & Bitter \\
\hline BGM1458 & Macapá (AP) & Landrace & White & Intermediate \\
\hline BGM1495 & Itiúba (BA) & Landrace & White & Intermediate \\
\hline BGM1537 & Paratinga (BA) & \begin{tabular}{|l} 
Landrace \\
\end{tabular} & White & Sweet \\
\hline BGM1576 & São João do Piauí (PI) & Landrace & White & Intermediate \\
\hline BGM1590 & Nazaré do Piauí (PI) & Landrace & White & Sweet \\
\hline BGM1615 & BR 407 (PI) & Landrace & White & Bitter \\
\hline BGM1640 & BR 135 (BA) & Landrace & White & Bitter \\
\hline BGM1667 & BR 316 (PA) & \begin{tabular}{|l|} 
Landrace \\
\end{tabular} & White & Sweet \\
\hline BGM1690 & Araripina (PE) & Landrace & Cream & Sweet \\
\hline BGM1698 & BR 163 (MS) & Landrace & White & Sweet \\
\hline BGM1704 & BR 230 (AM) & Landrace & Yellow & Bitter \\
\hline BGM1706 & BR 230 (AM) & Landrace & Cream & Sweet \\
\hline BGM1715 & BR 177 (AM) & Landrace & White & Sweet \\
\hline BGM1722 & Santo Antônio Jesus (BA) & Landrace & Cream & Sweet \\
\hline BGM1728 & Cruz das Almas (BA) & Landrace & White & Sweet \\
\hline BGM1772 & Chapadinha (MA) & Landrace & White & Sweet \\
\hline BGM1850 & Belém (PA) & Landrace & White & Sweet \\
\hline BGM1942 & Faro (PA) & Landrace & White & Bitter \\
\hline BGM1957 & Juruti (AM) & Landrace & Cream & Bitter \\
\hline BGM2028 & Araripina (PE) & Landrace & White & Bitter \\
\hline BGM2041 & Cruz das Almas (BA) & Breeding & Cream & Sweet \\
\hline BGM2052 & Pelotas (RS) & Landrace & White & Intermediate \\
\hline BRS Dourada & São Felipe (BA) & Breeding & Cream & Sweet \\
\hline BRS Formosa & Não informado (BA) & Breeding & White & Sweet \\
\hline BRS Jari & Cruz das Almas (BA) & Breeding & Yellow & Intermediate \\
\hline BRS Kiriris & Cruz das Almas (BA) & Breeding & White & Sweet \\
\hline BRS Poti Branca & Cruz das Almas (BA) & Breeding & White & Intermediate \\
\hline Corrente & Laje (BA) & Landrace & White & Bitter \\
\hline Fécula Branca & Marechal Cândido Rondon (PR) & Landrace & White & Sweet \\
\hline IAC90 & Marechal Cândido Rondon (PR) & Breeding & White & Sweet \\
\hline
\end{tabular}




\section{Data analysis}

A completely randomized design with three replications per accession (each repetition consists of three blades) was used, resulting in a total of 15 images per accession. Initially, the data were submitted to analysis of variance to investigate genetic variability among accessions. Because traits are measured using different units, resulting in different ranges and variances, the phenotypic means of quantitative traits NTG, GrAr, GrLe, GrWi, GrRo, and DMC were standardized, using the scale function $Z=\frac{X-\bar{X}}{S}$ (R Core Team, 2015), in which $Z$ is the standardized value of $X$, is the mean value of the traits, and $S$ is the standard deviation of the trait.

A principal component analysis (PCA), considering quantitative and qualitative data (pulp color of the root and classification of the cyanogenic compound content) was performed jointly using the PCAmixdata package (Chavent et al., 2014) implemented in the R program (R Core Team, 2015). In this case, the main algorithms were PCAmix (analysis of a mixture of numerical and categorical variables), PCArot (PCAmix rotation), and MFAmix (multiple factor analysis with mixed data within the data set).

The first four PCA axes were used to define the number of clusters by Euclidean distance, using the NbClust in R package (Charrad et al., 2014). Graphical analysis, and Hubert and $\mathrm{D}$ index statistics were used to determine the number of clusters based on the gain in the intra-cluster inertia group.

\section{RESULTS AND DISCUSSION}

\section{Analysis of quantitative traits}

The $F$-test was significant $(\mathrm{P}<0.001)$, confirming there were significant differences between the means of all quantitative traits related to starch granules in cassava accessions (Table 2). Therefore, cassava accessions were clustered to identify different groups in order to maximize genetic gain when using this germplasm to develop new varieties. The experimental coefficient of variation $(\mathrm{CV})$, which indicates the magnitude of experimental precision, was low $(<10 \%)$ for all traits except NTG. The CV reveals the optimal experimental accuracy needed to make inferences on important phenotypic differences between different cassava accessions.

Table 2. Summary of the analysis of variance. Average values, and ranges, of starch content and granule traits evaluated in cassava germplasm.

\begin{tabular}{l|c|c|c|c|c|c}
\hline Trait & & & & Minimum & Maximum & Average \\
\hline GrAr & MS $^{2}$ & P value & CV $^{3}$ & 81.00 & 178.58 & 113.37 \\
\hline GrWi & 14.07 & $<0.001$ & 7.91 & 9.24 & 14.03 & 10.96 \\
\hline GrLe & 11.11 & $<0.001$ & 4.55 & 9.25 & 14.01 & 10.99 \\
\hline GrRo & 11.10 & $<0.001$ & 4.57 & 0.85 & 0.91 & 0.88 \\
\hline NTG & 10.75 & $<0.001$ & 0.81 & 7.10 & 45.69 & 27.13 \\
\hline DMC & 15.42 & $<0.001$ & 12.1 & 28.01 & 39.70 & 33.94 \\
\hline
\end{tabular}

${ }^{1} \mathrm{GrAr}$ : granule area; GrWi: width of the granules; GrLe: length of the granule; GrRo: granule roundness; NTG: number of granules in $1 \mathrm{~g}$ of starch; DMC: dry matter content in the roots. ${ }^{2} \mathrm{MS}$ : mean square of the treatment; ${ }^{3} \mathrm{CV}$ : coefficient of variation.

In other species, variation in starch granule size and shape has also been associated with germplasm, climatic conditions, and agricultural practices used by farmers (Singh et

Genetics and Molecular Research 16 (2): gmr16029276 
al., 2012; Wani et al., 2012). In cassava, Kanagarasu et al. (2014) also reported significant morphological variability in the root quality of 52 landraces in India.

Positive and high-magnitude correlations were observed between the traits GrAr x GrWi (0.98), GrAr x GrLe (0.98), and GrWi x GrLe (0.99) (Figure 1). This indicates that the evaluation of only one of these traits may reflect variation in the others of the same direction and intensity. Moreover, a negative correlation of moderate magnitude was observed between PuCo x DMC (-0.43), indicating that yellowish accessions (related to total carotenoid content in cassava roots) tend to have lower dry matter content in their roots. This negative correlation is extremely undesirable in breeding programs, since cassava varieties with higher carotenoid content should also have greater DMC, considering the preference of farmers and industries.

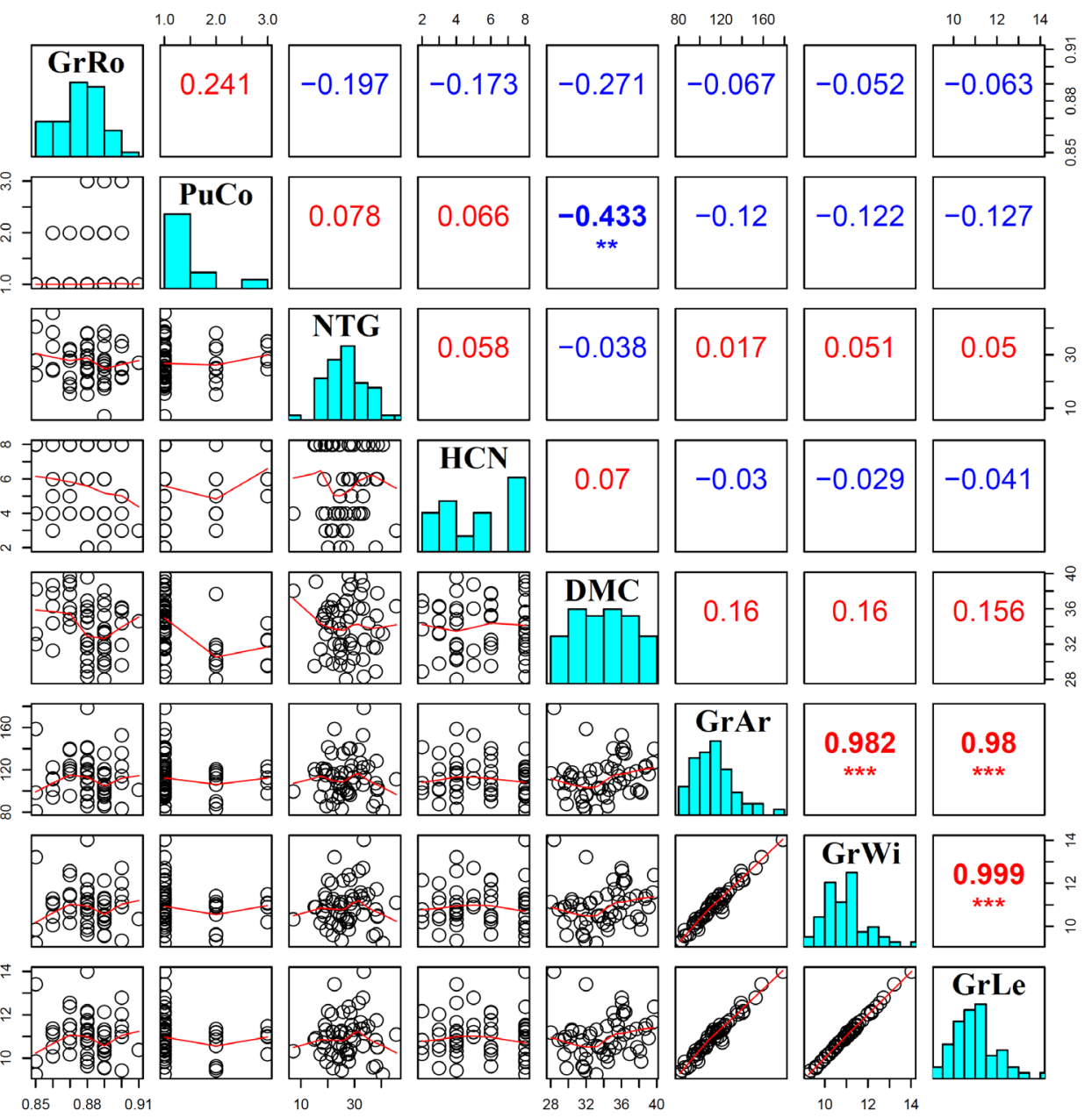

Figure 1. Pearson correlation between traits related to starch granule and root characteristics, based on an analysis of 56 cassava accessions. GrAr: granule area; GrWi: width of the granules; GrLe: length of the granule; GrRo: granule roundness; NTG: number of granules in $1 \mathrm{~g}$ of starch; DMC: dry matter content in the roots; HCN: cyanogen compound classification; PuCo: pulp color of the roots. Red text: positive correlations; Blue text: negative correlations; $* * *$ and $* *$ significant at $\mathrm{P}<0.001$ and $\mathrm{P}<0.01$, respectively.

Genetics and Molecular Research 16 (2): gmr16029276 
Previous reports on African cassava breeding programs noted a negative correlation between PuCo x DMC, which ranged from -0.22 to -0.29 (Esuma et al., 2012; Njoku et al., 2015). Njoku et al. (2015) indicated the need to identify new sources of African or Latin germplasm with yellow colored roots in an attempt to generate segregating populations to break the possible genetic linkage between these traits.

Microscopy revealed homogeneity in the shapes of the starch granules from the different cassava genotypes, which were predominantly circular and truncated (Figure 2). Although oval shapes have been reported in cassava (Mweta et al., 2008), this shape of granule was not observed in the present study. The morphology of starch granules may vary among species, but in general, these shapes are oval, ellipsoid, spherical, angular, and lenticular (Hoover, 2001; Singh et al., 2003). Cereals such as wheat, barley, and rye have a lenticular shape and large size, or a spherical shape and small size (Vamadevan and Bertoft, 2015).

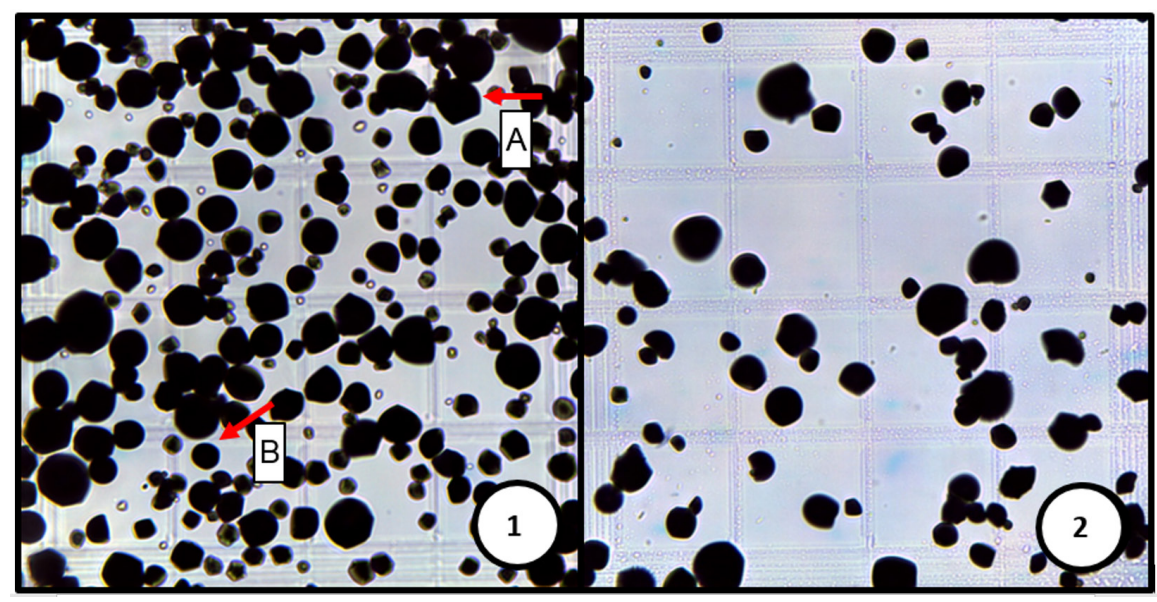

Figure 2. Microscopy of cassava starch granules at 400X magnification. (1) Accession BGM1537; (2) accession BGM1772. Arrows indicate the truncated (A) and circular (B) shapes.

Although the morphology of starch granules was similar between the evaluated cassava genotypes, significant differences in the number of granules and in granule size were identified (Table 2). The length and width of the starch granules exhibited similar ranges (9.24 to 14.03 $\mu \mathrm{m})$, averaging 10.96 and $10.99 \mu \mathrm{m}$ for width and length, respectively. This resulted in starch granule roundness that was close to 1 (range from 0.85 to 0.91 ; average 0.88 ). In addition, the length and width of the starch granules were reflected in granule area, which varied from 81.00 to $178.58 \mathrm{~mm}^{2}$, averaging $113.37 \mathrm{~mm}^{2}$. Granule size may vary with the developmental stage of the plant and the process of root tuberization from the central cambium (Leonel, 2007). However, the values obtained in the present study are consistent with those observed by other authors, with variation ranging from 10.0 to $17.0 \mu \mathrm{m}$ (Mweta et al., 2008; Wickramasinghe et al., 2009; Nuwamanya et al., 2010; Rolland-Sabaté et al., 2012; Mtunguja et al., 2016). In contrast, Rolland-Sabaté et al. (2012) showed that cassava genotypes with waxy starch tend to present large starch granules (between 20 and $40 \mu \mathrm{m}$ in size). Interestingly, various physicochemical properties, such as the amylose content by percentage of light transmittance, swelling power, and water binding capacity, are significantly correlated with the average size of starch granules in different plant species (Zhou et al., 1998).

Genetics and Molecular Research 16 (2): gmr16029276 
The number of granules in $1 \mathrm{~g}$ of starch also varied widely (from 7.10 to $45.69 \times 10^{6}$ ) with an average of $27.13 \times 10^{6}$. Importantly, some starch granules were damaged during the extraction process. However, these granules were excluded from the analysis to avoid bias.

The dry matter content in the roots was also quite variable between accessions (28.01 to $39.70 \%$ ), averaging $33.94 \%$ (Table 2). Other reports in the literature have shown that the dry matter content varies (16-53\%) depending on the genotypes and environmental conditions of cultivation (Kawuki et al., 2011; Esuma et al., 2012; Oliveira et al., 2015a).

\section{Cluster analysis}

PCA was used to cluster and reduce redundancy between the starch content and granule traits. The first four principal components (PC) accounted for most of the observed variability $(57.71 \%)$ in cassava germplasm for starch granule traits (Table 3). PC1 accounted for $24.2 \%$ of the phenotypic variation in the cassava germplasm collection and the quantitative traits GrAr, GrLe, and GrWi were the most important for explaining the variation in this PC. PC2 represented $12.87 \%$ of the total variation, and the quantitative traits GrRo and DMC, and qualitative trait (pulp color of the roots) were the most important for determining this variation. In contrast, $\mathrm{PC} 3$ explained $11.12 \%$ of the variation, primarily due to variation in the quantitative trait (NTG) and qualitative trait (HCN). PC4 accounted for $9.52 \%$ of the variation, and the most important variables were GrRo and HCN. The other PC presented low discriminatory power of cassava accessions and was therefore not considered in subsequent analyses.

Table 3. Absolute contributions of quantitative and qualitative traits (sum of the absolute contributions of qualitative variables), with eigenvalues and contribution to the total variation for the first four main principal components (PCs) from the principal component analysis with mixed data.

\begin{tabular}{l|c|c|c|c}
\hline Traits & PC1 & PC2 & PC3 & PC4 \\
\hline Cyanogen compounds classification & 0.05 & 0.25 & 0.61 & 0.57 \\
\hline Pulp color & 0.11 & 0.56 & 0.36 & 0.22 \\
\hline Granule area & 0.97 & 0.15 & -0.07 & -0.01 \\
\hline Width of the granules & 0.98 & 0.15 & -0.04 & 0.01 \\
\hline Length of the granules & 0.98 & 0.15 & -0.05 & -0.01 \\
\hline Granule roundness & -0.15 & 0.57 & -0.12 & 0.61 \\
\hline Number of granules in 1g of starch & 0.07 & -0.02 & 0.66 & -0.24 \\
\hline Dry matter content & 0.31 & -0.68 & 0.05 & 0.11 \\
\hline Eigenvalues & 3.15 & 1.67 & 1.45 & 1.24 \\
\hline Variation explained (\%) & 24.20 & 12.87 & 11.12 & 9.52 \\
\hline
\end{tabular}

Macromolecular characteristics, such as crystallinity, grain size, and thermal properties of waxy and non-waxy cassava clones, as well as waxy starch from potato and corn, were used to classify the accessions with specific properties based on the PCA (Rolland-Sabate et al., 2012). Rolland-Sabaté et al. (2012) observed that (a) the two PCs accounted for 55 and $27 \%$ of the total variance of the data, respectively; (b) the amylose content, the wavelength at maximum absorption of the iodine complexes with starch polymers $\left(1_{\max }\right)$, and the apparent particle density (dGappw) were grouped closely together; (c) there was a strong correlation between amylose content and $1_{\max }$; and (d) amylose content and dGappw represent independent traits associated with PC1. Therefore, molecular characteristics associated with starch granules tend to reveal an important organization in global starch diversity.

Genetics and Molecular Research 16 (2): gmr16029276 
Of the 23 criteria used for clustering in the NbClust package (Charrad et al., 2014), eight $(35 \%)$ were noted for the formation of four clusters, based on the analysis of the four main components. Therefore, clustering of cassava accessions based on the root and starch granule traits was based on the criteria of Hartigan, TraceW, Rubin, Cindex, Silhouette, Ratkowsky, PtBiserial, and SDindex.

Cluster 1 consisted of 11 accessions: one improved clone (98150-06) and 10 landraces (BGM1171, BGM1942, BGM1412, BGM1495, BGM1576, BGM1429, BGM1376, BGM1772, BGM1590, and BGM1715). This cluster presented the highest average values for GrAr, GrWi, GrLe, and DMC (Figure 3). Cluster 2 was formed of three improved genotypes (BGM2041, BRS Dourada, and BRS Formosa) and 11 landraces (BGM1957, BGM0889, BGM1127, BGM1313, BGM1537, BGM1698, BGM1850, Fécula Branca, BGM1706, BGM1690, BGM1722, and BGM0250). The notable traits of this cluster were the low DMC and NTG (Figure 3).
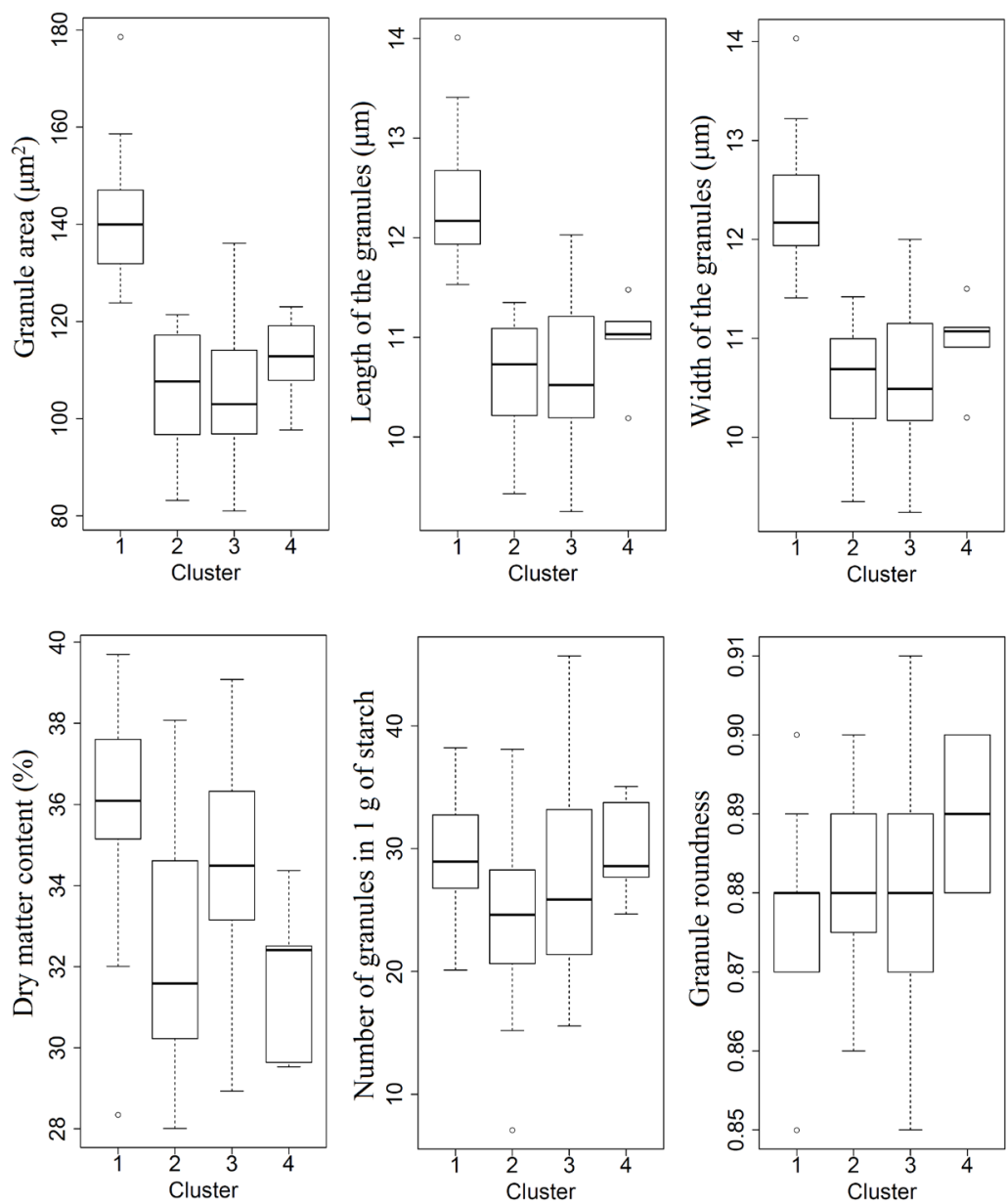

Figure 3. Box plot of traits related to starch granule and root quality in 56 cassava accessions, considering four clusters.

Genetics and Molecular Research 16 (2): gmr16029276 
Three improved varieties (BRS Kiriris, BRS Poti Branca, and IAC90) and 22 landraces (BGM0394, BGM0540, BGM0670, BGM0982, BGM0989, BGM1081, BGM1174, BGM1202, BGM1327, BGM1437, BGM1615, BGM1640, BGM2028, Corrente, BGM1458, BGM2052, BGM1110, BGM1180, BGM1667, BGM0620, BGM1370, and BGM1728) were allocated on Cluster 3. On average, Cluster 3 presented small starch granule size (small GrAr, GrLe, and GrWi) and high DMC. Avijala et al. (2015) reported that the traits harvest index, production of commercial roots, and dry matter content in the roots were of low importance when studying the genetic diversity among 21 genotypes of cassava in Mozambique. However, DMC was important as it contributed to the differentiation of different clusters of cassava accessions evaluated in the present study, as noted by Oliveira et al. (2015a).

One improved variety (BRS Jari) and four germplasm accessions (BGM1078, BGM1704, BGM1178, and BGM0507) formed Cluster 4. The accessions of this cluster have lower DMC and medium-sized starch granules with a tendency to be more rounded compared with those of other accessions (Figure 3).

Genetic diversity clustering is extremely important for planning breeding programs in order to obtain hybrids and train populations for future uses. In general, accessions present in different clusters are promising in crosses performed to generate populations with a high level of segregation. However, as cassava is a highly heterozygous species, considerable diversity of genotypic combinations can be obtained even through the use of selfing. Therefore, accessions belonging to the same group can be crossed to achieve more rapid genetic gains focused on four main subjects in the development of varieties: biofortifying (increasing carotenoid content in roots), new sweet cassava varieties with white pulp color, and varieties for industrial purposes with large and small starch granules.

Considering a minimum of $30 \% \mathrm{DMC}$, low-to-intermediate cyanogen compound content, and cream-to-yellow pulp color, the accessions BGM1178, BGM1722, BGM1690, BGM0250, and BRS Dourada are considered the most promising. Conversely, considering the generation of segregating populations for sweet cassava with a minimum of $35 \%$ DMC, low cyanogenic compounds and white pulp color, the most promising accessions are BGM1590, BGM1850, BGM1180, BGM0620, BGM1429, BGM1728, BGM1376, BGM1715, and BGM1313.

For industrial purposes, and therefore independent of the cyanogenic compound content but with a minimum of $35 \% \mathrm{DMC}$, the cassava accessions most suitable for generating segregating populations with small starch granules, are BGM0540, BRS Dourada, BGM0982, BGM1127, BGM1437, BGM1174, and BGM0989. Accessions with these characteristics but with larger starch granules are BGM1495, BGM1715, BGM1376, BGM1728, BGM1429, BGM1412, and BGM1171. As small starch granules resemble those of lipids, cassava varieties producing small starch granules may be useful in the food industry as fat replacers (Leonel, 2007). Furthermore, according to Ceballos et al. (2008), genotypes with small starch granules have increased potential for use in the biofuel industry.

Considering paste properties using different starch sizes, Singh et al. (2012) reported that the small starch granules from rice beans (Vigna umbellata) were inversely related to starch swelling power, and therefore, inbred lines with a higher proportion of small starch granules were able to absorb water at higher temperatures. Additionally, those authors reported a positive correlation between peak viscosity, retrogradation, and setback when testing lines with large starch granules. Therefore, it is possible that the starch characteristics reported for rice bean can reflect different properties of the cassava accessions belonging to different groups identified by the PCA analysis.

Genetics and Molecular Research 16 (2): gmr16029276 
The association of the clusters formed by the PCA and qualitative characterization regarding pulp color of the roots and the cyanogenic compound content are shown in Figures 4 and 5, respectively. The clustering formed by the PCA was very effective at classifying cassava accessions with yellow pulp in Cluster 4 and cream pulp in Cluster 2, although some accessions remained in the latter group with white roots (BGM1698, BGM1313, BGM1850, BGM1537, Fécula Branca, and BRS Formosa) (Figure 4). The accessions belonging to Clusters 1 and 3 presented a white pulp color.

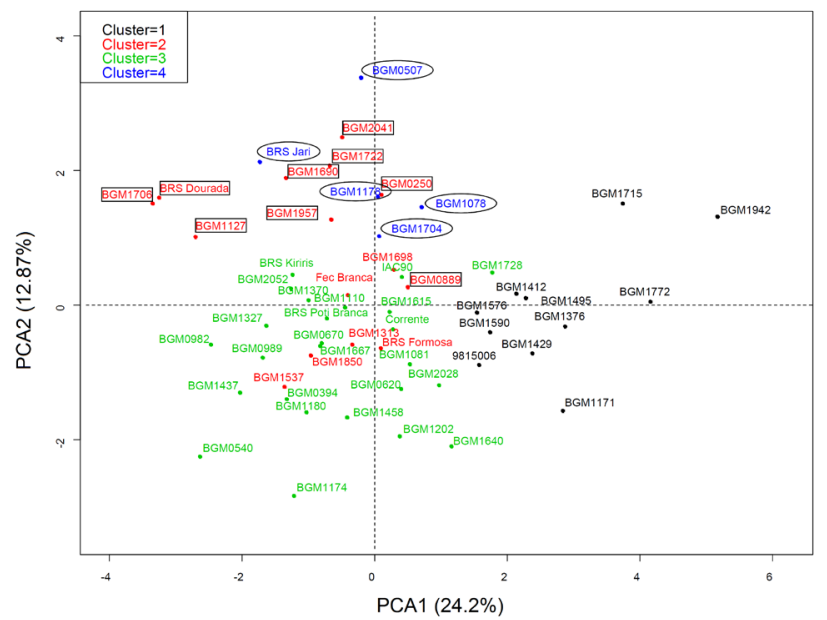

Figure 4. Two-dimensional clustering of the distribution of 56 cassava accessions based on root traits and starch granules, obtained by principal component analysis (PCA). The four identified clusters are represented by different colors. Accessions marked with rectangular and oval borders have roots with cream and yellow pulp color, respectively. The other accessions presented white pulp roots.

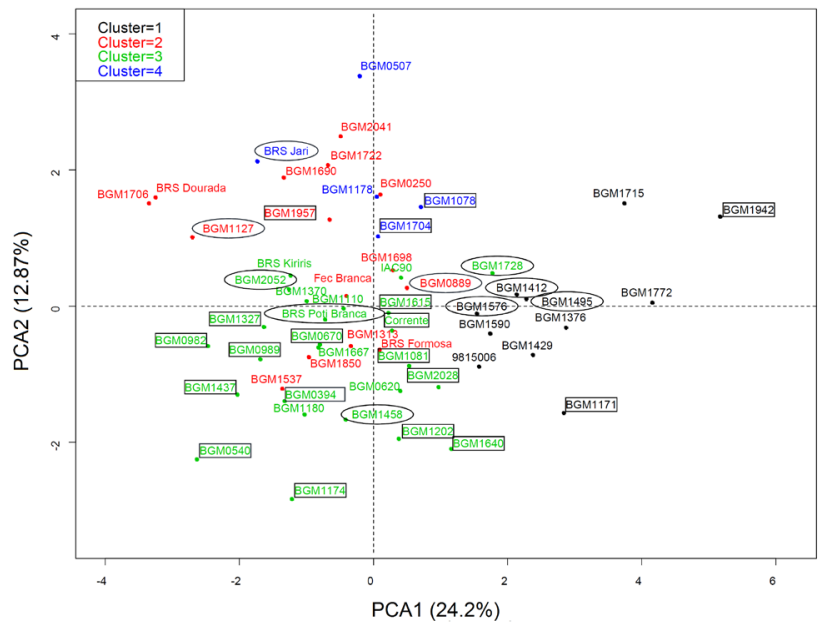

Figure 5. Two-dimensional clustering of the distribution of 56 cassava accessions based on root traits and starch granules, obtained by PCA. The four identified groups are represented by different colors. Accessions marked with rectangular and oval borders contain high (bitter cassava) and intermediate levels of cyanogenic compounds, respectively. The other accessions contain low levels of cyanogenic compounds in their roots (sweet cassava).

Genetics and Molecular Research 16 (2): gmr16029276 
When estimating genetic variation between cassava accessions, Oliveira et al. (2015a) found a weak association (0.38) between the clusters formed with quantitative data and the clusters formed by the joint analysis (qualitative data: binomial and multicategoric, and quantitative data). This indicates that analysis of quantitative and qualitative data may consider genetic variations in distinct genomic regions. However, quantitative data related to cassava starch granule traits were accurate for clustering cassava accessions with yellow and cream pulp in distinct groups (Figure 4).

Regarding the classification of cyanogenic compound content, there was no consistency in the clustering proposed by the PCA, as bitter accessions ( $\mathrm{HCN}>100 \mathrm{ppm})$ were allocated in Cluster 1 (BGM1171 and BGM1942), Cluster 2 (BGM1957), Cluster 3 (BGM0394, BGM0540, BGM0670, BGM0982, BGM0989, BGM1081, BGM1174, BGM1202, BGM1327, BGM1437, BGM1615, BGM1640, BGM2028, and Corrente) and Cluster 4 (BGM1078 and BGM1704) (Figure 5). This was also observed with other classifications (low and intermediate levels of cyanogenic compounds). Oliveira et al. (2015b) used the affinity propagation algorithm to cluster 474 cassava accessions based on the following traits: starch yield, dry matter content, amylose, and cyanogenic compound content in the roots. These authors also reported difficulty in the classification of cassava accessions based exclusively on cyanogenic compound content, due to the large scale of this trait, especially in two groups, and the absence of an association between the genetic structure of accessions and the classification of bitter and sweet cassava.

The identification and use of accessions available in cassava germplasm banks may contribute to improvements in the productivity of fresh roots and starch (Table 4). However, despite the constant need to develop novel and more productive cassava varieties, it is necessary to consider current trends within the food industry, and farmers searching for native starches with special features that could replace chemically modified varieties or open new market opportunities (Leonel, 2007). Therefore, breeding programs should also seek to improve the starch quality produced by new varieties. In this regard, Brazil has a strategic advantage since it is considered the center of genetic diversity of M. esculenta (Olsen, 2004; Isendahl, 2011), and thus has sufficient genetic diversity to meet these demands. As demonstrated, the analysis of genetic relationships among cassava accessions based on root traits and starch granules is an important component of breeding programs, because it provides crucial information required for establishing segregated populations stratified by targeted goals for quality starch.

\section{Conflicts of interest}

The authors declare no conflict of interest.

\section{ACKNOWLEDGMENTS}

The authors thank the Fapesb, CAPES, and CNPq for the financial assistance and scholarship support.

\section{REFERENCES}

\footnotetext{
Avijala MF, Bhering LL, Peixoto LA, Cruz CD, et al. (2015). Genetic diversity revealed dissimilarity among Mozambican cassava cultivars. Aust. J. Crop Sci. 9: 772-780.

Baguma Y (2004). Regulation of Starch Synthesis in Cassava. Doctoral thesis, Swedish University of Agricultural Sciences - Upassala.
}

Genetics and Molecular Research 16 (2): gmr16029276 
Table 4. Mean values of the starch traits analyzed in cassava accessions.

\begin{tabular}{|c|c|c|c|c|c|c|c|}
\hline Genotype & DMC & $\mathrm{HCN}$ & GrAr & GrLe & GrWi & NTG & GrRo \\
\hline $98150-06$ & 39.57 & 6 & 126.44 & 11.66 & 11.59 & 32.26 & 0.88 \\
\hline BGM0250 & 31.30 & 5 & 111.91 & 11.21 & 11.03 & 24.62 & 0.86 \\
\hline BGM0394 & 33.99 & 8 & 95.43 & 10.19 & 10.16 & 21.37 & 0.87 \\
\hline BGM0507 & 29.64 & 5 & 107.90 & 10.98 & 10.91 & 24.67 & 0.90 \\
\hline BGM0540 & 33.17 & 8 & 81.00 & 9.25 & 9.24 & 40.57 & 0.85 \\
\hline BGM0620 & 36.32 & 3 & 111.43 & 11.10 & 11.10 & 45.69 & 0.86 \\
\hline BGM0670 & 33.45 & 8 & 103.01 & 10.52 & 10.50 & 38.68 & 0.89 \\
\hline BGM0889 & 37.68 & 6 & 118.75 & 11.35 & 11.42 & 32.26 & 0.87 \\
\hline BGM0982 & 31.67 & 8 & 85.80 & 9.58 & 9.57 & 37.05 & 0.89 \\
\hline BGM0989 & 32.00 & 8 & 96.86 & 9.96 & 9.97 & 24.46 & 0.88 \\
\hline BGM1078 & 34.37 & 8 & 123.06 & 11.48 & 11.50 & 35.05 & 0.90 \\
\hline BGM1081 & 36.97 & 8 & 116.14 & 11.21 & 11.27 & 22.02 & 0.89 \\
\hline BGM1110 & 28.93 & 2 & 107.64 & 10.85 & 10.80 & 37.86 & 0.88 \\
\hline BGM1127 & 31.62 & 6 & 90.29 & 9.63 & 9.64 & 38.08 & 0.88 \\
\hline BGM1171 & 39.70 & 8 & 139.96 & 12.37 & 12.40 & 27.79 & 0.87 \\
\hline BGM1174 & 38.23 & 8 & 98.57 & 9.85 & 9.85 & 27.90 & 0.85 \\
\hline BGM1178 & 32.51 & 6 & 112.87 & 11.16 & 11.11 & 33.75 & 0.88 \\
\hline BGM1180 & 36.94 & 2 & 98.57 & 10.20 & 10.21 & 27.19 & 0.88 \\
\hline BGM1202 & 39.08 & 8 & 116.00 & 10.94 & 10.91 & 15.57 & 0.87 \\
\hline BGM1313 & 35.83 & 4 & 107.65 & 10.70 & 10.62 & 23.83 & 0.88 \\
\hline BGM1327 & 31.42 & 8 & 94.81 & 10.18 & 10.17 & 17.36 & 0.89 \\
\hline BGM1370 & 33.31 & 3 & 102.34 & 10.56 & 10.48 & 25.86 & 0.89 \\
\hline BGM1376 & 36.09 & 4 & 138.85 & 12.56 & 12.57 & 31.61 & 0.87 \\
\hline BGM1412 & 36.45 & 6 & 135.41 & 12.13 & 12.14 & 25.76 & 0.89 \\
\hline BGM1429 & 36.24 & 2 & 141.38 & 12.17 & 12.16 & 20.12 & 0.88 \\
\hline BGM1437 & 34.49 & 8 & 85.88 & 9.84 & 9.84 & 19.55 & 0.88 \\
\hline BGM1458 & 37.80 & 6 & 101.07 & 10.52 & 10.47 & 38.51 & 0.86 \\
\hline BGM1495 & 35.08 & 6 & 140.39 & 12.11 & 12.17 & 28.49 & 0.88 \\
\hline BGM1537 & 34.37 & 4 & 93.94 & 10.09 & 10.05 & 24.08 & 0.86 \\
\hline BGM1576 & 35.22 & 6 & 128.43 & 11.76 & 11.73 & 38.21 & 0.88 \\
\hline BGM1590 & 38.76 & 5 & 123.85 & 11.53 & 11.41 & 28.93 & 0.87 \\
\hline BGM1615 & 30.39 & 8 & 113.07 & 11.31 & 11.25 & 29.58 & 0.88 \\
\hline BGM1640 & 38.68 & 8 & 122.34 & 11.38 & 11.29 & 33.18 & 0.86 \\
\hline BGM1667 & 33.69 & 2 & 103.17 & 10.50 & 10.50 & 24.62 & 0.89 \\
\hline BGM1690 & 30.24 & 4 & 106.07 & 10.56 & 10.56 & 33.20 & 0.89 \\
\hline BGM1698 & 30.43 & 4 & 117.44 & 11.27 & 11.15 & 25.11 & 0.88 \\
\hline BGM1704 & 32.41 & 8 & 119.14 & 11.03 & 11.07 & 28.57 & 0.88 \\
\hline BGM1706 & 29.82 & 3 & 87.65 & 9.54 & 9.59 & 21.94 & 0.89 \\
\hline BGM1715 & 36.04 & 5 & 152.78 & 12.79 & 12.73 & 33.23 & 0.90 \\
\hline BGM1722 & 30.21 & 4 & 114.83 & 11.00 & 10.96 & 19.34 & 0.89 \\
\hline BGM1728 & 36.19 & 3 & 136.14 & 12.03 & 12.00 & 21.48 & 0.90 \\
\hline BGM1772 & 32.01 & 4 & 158.62 & 13.41 & 13.22 & 22.48 & 0.85 \\
\hline BGM1850 & 38.08 & 4 & 99.53 & 10.34 & 10.33 & 7.10 & 0.89 \\
\hline BGM1942 & 28.35 & 8 & 178.58 & 14.01 & 14.03 & 33.53 & 0.88 \\
\hline BGM1957 & 29.53 & 8 & 120.65 & 10.86 & 10.90 & 15.19 & 0.88 \\
\hline BGM2028 & 35.58 & 8 & 119.07 & 11.53 & 11.50 & 18.99 & 0.87 \\
\hline BGM2041 & 28.01 & 4 & 117.00 & 11.18 & 11.14 & 26.79 & 0.89 \\
\hline BGM2052 & 32.05 & 6 & 96.40 & 10.37 & 10.36 & 28.28 & 0.89 \\
\hline BRS Dourada & 31.92 & 4 & 83.19 & 9.43 & 9.35 & 25.13 & 0.90 \\
\hline BRS Formosa & 34.85 & 4 & 121.43 & 10.73 & 10.69 & 18.09 & 0.87 \\
\hline BRS Jari & 29.53 & 6 & 97.70 & 10.19 & 10.20 & 27.68 & 0.89 \\
\hline BRS Kiriris & 34.61 & 3 & 101.23 & 10.39 & 10.36 & 27.08 & 0.91 \\
\hline BRS Poti Branca & 35.27 & 6 & 105.53 & 10.49 & 10.49 & 18.61 & 0.89 \\
\hline Corrente & 35.68 & 8 & 114.07 & 11.22 & 11.15 & 21.86 & 0.90 \\
\hline Fécula Branca & 31.58 & 4 & 106.87 & 10.82 & 10.77 & 29.71 & 0.88 \\
\hline IAC90 & 33.15 & 3 & 120.70 & 11.31 & 11.33 & 19.34 & 0.89 \\
\hline
\end{tabular}

DMC: dry matter content in the roots; HCN: cyanide coumpound; GrAr: granule area; GrLe: length of the granule; GrWi: width of the granules; NTG: number of granules in $1 \mathrm{~g}$ of starch; GrRo: granule roundness.

Genetics and Molecular Research 16 (2): gmr16029276 
Ceballos H, Fahrney K, Howeler R and Ospina B (2008). Cassava potential for bioethanol. In: Symposium - Biofuels in Developing Countries: Opportunities and Risks, Houston, 625-628.

Ceballos H, Sánchez T, Morante N, Fregene M, et al. (2007). Discovery of an amylose-free starch mutant in cassava (Manihot esculenta Crantz). J. Agric. Food Chem. 55: 7469-7476. http://dx.doi.org/10.1021/jf070633y

Charrad M, Ghazzali N, Boiteau V and Niknafs A (2014). Nbclust: an R package for determining the relevant number of clusters in a data set. J. Stat. Softw. 61: 1-36. http://dx.doi.org/10.18637/jss.v061.i06

Chavent M, Kuentz-Simonet V, Labenne A, Saracco J (2014). Multivariate analysis of mixed data: The PCAmixdata R package. arXiv preprint arXiv 1411: 4911

Copeland L, Blazek J, Salman H and Tang MC (2009). Form and functionality of starch. Food Hydrocoll. 23: 1527-1534. http://dx.doi.org/10.1016/j.foodhyd.2008.09.016

Esuma W, Rubaihayo P, Pariyo A, Kawuki RS, et al. (2012). Genetic diversity of provitamin A cassava in Uganda. J. Plant Stud. 1: 60-71. http://dx.doi.org/10.5539/jps.v1n1p60

Fukuda WMG, Guevara CL, Kawuki R and Ferguson ME (2010). Selected morphological and agronomic descriptors for the characterization of cassava. International Institute of Tropical Agriculture (IITA), Ibadan, Nigeria.

Hoover R (2001). Composition, molecular structure, and physicochemical properties of tuber and root starches: a review. Carbohydr. Polym. 45: 253-267. http://dx.doi.org/10.1016/S0144-8617(00)00260-5

Howeler R, Lutaladio N and Thomas G (2013). Save and Grow: Cassava: A Guide to Sustainable Production Intensification, Food and Agriculture Organization of the United Nations Rome.

Isendahl C (2011). The domestication and early spread of manioc (Manihot esculenta Crantz): A brief synthesis. Lat. Am. Antiq. 22: 452-468. http://dx.doi.org/10.7183/1045-6635.22.4.452

Kanagarasu S, Justinraj F, Prem Joshua J, Ganeshram S, et al. (2014). Exploration and collection of cassava (Manihot esculenta Crantz) in Western Ghats and characterisation for industrial use. Res. J. Recent Sci. 3: 248-255.

Kawano K, Daza P, Amaya A, Ríos M, et al. (1978). Evaluation of cassava germplasm for productivity. Crop Sci. 18: $377-$ 380. http://dx.doi.org/10.2135/cropsci1978.0011183X001800030006x

Kawuki RS, Ferguson M, Labuschane MT, Herselman L, et al. (2011). Variation in qualitative and quantitative traits of cassava germplasm from selected national breeding programmes in sub-Saharan Africa. Field Crops Res. 122: 151156. http://dx.doi.org/10.1016/j.fcr.2011.03.006

Lawal OS, Lapasin R, Bellich B, Olayiwola TO, et al. (2011). Rheology and functional properties of starches isolated from five improved rice varieties from West Africa. Food Hydrocoll. 25: 1785-1792. http://dx.doi.org/10.1016/j. foodhyd.2011.04.010

Leonel M (2007). Análise da forma e tamanho de grânulos de amidos de diferentes fontes botânicas. Ciênc. Tecnol. Aliment. 27: 579-588. http://dx.doi.org/10.1590/S0101-20612007000300024

Lindeboom N, Chang PR and Tyler R (2004). Analytical, biochemical and physicochemical aspects of granule size, with emphasis on small granule starches: A review. Starch 56: 89-99. http://dx.doi.org/10.1002/star.200300218

Molenda M, Stasiak M, Horabik J, Fornal J, et al. (2006). Microstructure and mechanical parameters of five types of starch. Pol. J. Food Nutr. Sci. 15: 161.

Mtunguja MK, Thitisaksakul M, Muzanila YC, Wansuksri R, et al. (2016). Assessing variation in physicochemical, structural, and functional properties of root starches from novel Tanzanian cassava (Manihot esculenta Crantz.) landraces. Starch 68: 1-14. http://dx.doi.org/10.1002/star.201500179

Mweta DE, Labuschane MT, Koen E, Benesi IR, et al. (2008). Some properties of starches from cocoyam (Colocasia esculenta) and cassava (Manihot esculenta Crantz.) grown in Malawi. Afr. J. Food Sci. 2: 102-111.

Njoku DN, Gracen E, Offei SK, Asante IK, et al. (2015). Parent-offspring regression analysis for total carotenoids and some agronomic traits in cassava. Euphytica 206: 657-666. http://dx.doi.org/10.1007/s10681-015-1482-4

Nuwamanya E, Baguma Y, Emmambux N, Taylor J, et al. (2010). Physicochemical and functional characteristics of cassava starch in Ugandan varieties and their progenies. J. Plant Breed. Crop Sci. 2: 1-11.

Oliveira EJ, Oliveira Filho OS and Santos VS (2015a). Classification of cassava genotypes based on qualitative and quantitative data. Genet. Mol. Res. 14: 906-924. http://dx.doi.org/10.4238/2015.February.2.14

Oliveira EJ, Santana FA, Oliveira LA and Santos S (2015b). Genotypic variation of traits related to quality of cassava roots using affinity propagation algorithm. Sci. Agric. 72: 53-61. http://dx.doi.org/10.1590/0103-9016-2014-0043

Olsen KM (2004). SNPs, SSRs and inferences on cassava's origin. Plant Mol. Biol. 56: 517-526. http://dx.doi.org/10.1007/ s11103-004-5043-9

Onwuka GI (2005). Food Analysis and Instrumentation. Theory and Practice. Napthali Prints.

Rolland-Sabaté A, Sánchez T, Buléon A, Colonna P, et al. (2012). Structural characterization of novel cassava starches with low and high-amylose contents in comparison with other commercial sources. Food Hydrocoll. 27: 161-174. http://dx.doi.org/10.1016/j.foodhyd.2011.07.008

Genetics and Molecular Research 16 (2): gmr16029276 
R Core Team (2015). R: A language and environment for statistical computing. R Foundation for Statistical Computing, Vienna, Austria. Available at [http://www.R-project.org/]. Accessed November 07, 2015.

Sanoussi AF, Loko LY, Ahissou H, Adjahi AK, et al. (2015). Diversity physicochemical and technological characterization of elite cassava (Manihot esculenta Crantz) cultivars of Bantè, a district of Central Benin. Scientific World J. ID 674201.

Schneider CA, Rasband WS and Eliceiri KW (2012). NIH Image to ImageJ: 25 years of image analysis. Nat. Methods 9: 671-675. http://dx.doi.org/10.1038/nmeth.2089

Singh N, Singh J, Kaur L, Sodhi NS, et al. (2003). Morphological, thermal and rheological properties of starches from different botanical sources. Food Chem. 81: 219-231. http://dx.doi.org/10.1016/S0308-8146(02)00416-8

Singh N, Kaur S, Isono N, Ichihashi Y, et al. (2012). Diversity in characteristics of starch amongst rice bean (Vigna umbellate) germplasm: Amylopectin structure, granules size distribution, thermal and rheology. Food Res. Int. 46: 194-200. http://dx.doi.org/10.1016/j.foodres.2011.11.015

Taggart P and Mitchell JR (2009). Starch. In: Hanbook of hydrocolloids. (Phillips GO and Williams PA, eds.). Cambridge. CRC Press, 108-141.

Taylor NJ, Fauquet CM and Tohme J (2012). Overview of Cassava special issue. Trop. Plant Biol. 5: 1-3. http://dx.doi. org $/ 10.1007 / \mathrm{s} 12042-012-9098-5$

Tonukari NJ (2004). Cassava and the future of starch. Electron. J. Biotechnol. 7: 5-8. http://dx.doi.org/10.2225/vol7issue1-fulltext-9

Upadhyaya HD, Dwivedi SL, Gowda CLL and Singh S (2007). Identification of diverse germplasm lines for agronomic traits in a chickpea (Cicer arietinum L.) core collection for use in crop improvement. Field Crops Res. 100: 320-326. http://dx.doi.org/10.1016/j.fcr.2006.08.008

Vamadevan V and Bertoft E (2015). Structure-function relationships of starch components. Starch 67: 55-68. http://dx.doi. org/10.1002/star.201400188

Wani AA, Singh P, Shah MA, Schweiggert-Weisz U, et al. (2012). Rice starch diversity: effects on structural, morphological, thermal, and physicochemical properties - a review. Compr. Rev. Food Sci. Food Saf. 11: 417-436. http://dx.doi. org/10.1111/j.1541-4337.2012.00193.x

Wickramasinghe HAM, Takigawa S, Matsuura-Endo C, Yamauchi H, et al. (2009). Comparative analysis of starch properties of different root and tuber crops of Sri Lanka. Food Chem. 112: 98-103. http://dx.doi.org/10.1016/j. foodchem.2008.05.046

Zhou M, Robards K, Glennie-Holmes M and Helliwell S (1998). Structure and pasting properties of oat starch. Cereal Chem. 75: 276-281. http://dx.doi.org/10.1094/CCHEM.1998.75.3.273

Genetics and Molecular Research 16 (2): gmr16029276 